\title{
A Challenging Case of Acute Limb Ischemia Complicating an Endocarditis: Case Report in Mohamed VI University Hospital
}

\author{
M. A. Khouchab*, S. Jourani, N. Charei, M. EL Hattaoui
}

Department of Cardiology, Mohamed VI University Hospital, Marrakech, Morocco

DOI: $10.36347 /$ sasjm.2020.v06i03.001

| Received: 03.03.2020 | Accepted: 10.03.2020 | Published: 13.03.2020

*Corresponding author: Mohamed Anas Khouchab

Abstract

Case Report

Infective endocarditis (IE) occurs at a rate of approximately 25-50/1000000 people per year in patients with a preexisting cardiac pathology in $2 / 3$ of the cases. Despite the therapeutic advances, and the developpement of new surgical approches, the morbidty and mortality related to infectious endocarditis remains high. The epidemiological profile of infective endocarditis has changed considerably in recent decades in Morocco. Despite the efforts made to eradicate rheumatoid arthritis, rheumatic valve disease remains a public health problem in our context. Antibiotic therapy is the cornerstone of the treatment of endocarditis. However, some dreadful complications can occur, even with undergoing antibiotic therapy. Systemic embolism is one of them and occurs in $22 \%-50 \%$ of IE patients; emboli may involve major arteries, mostly affecting the central nervous system as well as other organs. However, peripheral arterial emboli that result from bacterial endocarditis may be silent or catastrophic. The present report presents an unusual case of infectious endarditis complicated with peripheral arterial embolism of the common femoral artery and acute lower limb ischemia. The patient underwent urgent Fogarty embolectomy and a delayed surgical procedure for mitral valve replacement and tricuspid valve repair. Proper emergency management is discussed and conclusions are made regarding indications of conservative and invasive treatment.

Keywords: Infective endocarditis, acute limb ischemia, Fogarty embolectomy, mitral valve replacement.

Copyright @ 2020: This is an open-access article distributed under the terms of the Creative Commons Attribution license which permits unrestricted use, distribution, and reproduction in any medium for non-commercial use (NonCommercial, or CC-BY-NC) provided the original author and source are credited.

\section{INTRODUCTION}

Infective endocarditis (IE) occurs at a rate of approximately 25-50/1000000 people per year in patients with a preexisting cardiac pathology in $2 / 3$ of the cases. Despite the therapeutic advances, and the developpement of new surgical approches, the morbidty and mortality related to infectious endocarditis remains high .The epidemiological profile of infective endocarditis has changed considerably in recent decades in Morocco. Despite the efforts made to eradicate rheumatoid arthritis, rheumatic valve disease remains a public health problem in our context. Antibiotic therapy is the cornerstone of the treatment of endocarditis. However, some dreadful complications can occur, even with undergoing antibiotic therapy. Systemic embolism is one of them and occurs in $22 \%-50 \%$ of IE patients; emboli may involve major arteries, mostly affecting the central nervous system as well as other organs. However, peripheral arterial emboli that result from bacterial endocarditis may be silent or catastrophic.

\section{CASE REPORT}

A 62-year-old patient was admitted to the cardiology department for the management of infectious endocarditis diagnosed by modified Duke criteria:

- $\quad 21 * 12 \mathrm{~mm}$ vegetation on the atrial leaflet of the mitral valve with mitral stenosis (Fig-1).

- Positive blood cultures with staphylococcus aureus (Fig-2).

- $\quad$ Prolonged fever $\left(39^{\circ}\right.$ during 1 month)

- Polyarthralgia

- $\mathrm{CRP}$ at $160 \mathrm{mg} / \mathrm{l}, \mathrm{ESR}=110 \mathrm{~mm}, \mathrm{WC}: 12000$ cell $/ \mathrm{mm} 3$

The patient fever subsided after treatment with antibiotics was initiated $(2 \mathrm{~g}$ of ceftriaxone and $160 \mathrm{mg}$ of gentamycin); However, the patient presented on the 10th day of hospitalization an acute pain, coldness, paresis and pallor of the right lower limb. We immediatly performed an arterial doppler ultrasound of the right lower limb that showed a thromboembolic occlusion of the right iliofemral artery (Fig-3). 
M. A. Khouchab et al., SAS J Med, March, 2020; 6(3): 80-83

The patient immediately underwent a revascularization with $4 \mathrm{~F}$ Fogarty catheter. A long thrombus molding the ilio femoral axis was removed (Fig-4).
We performed a doppler ultrasound after the revascularization that showed normal flow in both lower limbs arteries (Fig-5).

The patient underwent a mitral valve replacement with tricuspid plasty in his second week of hospitalization.

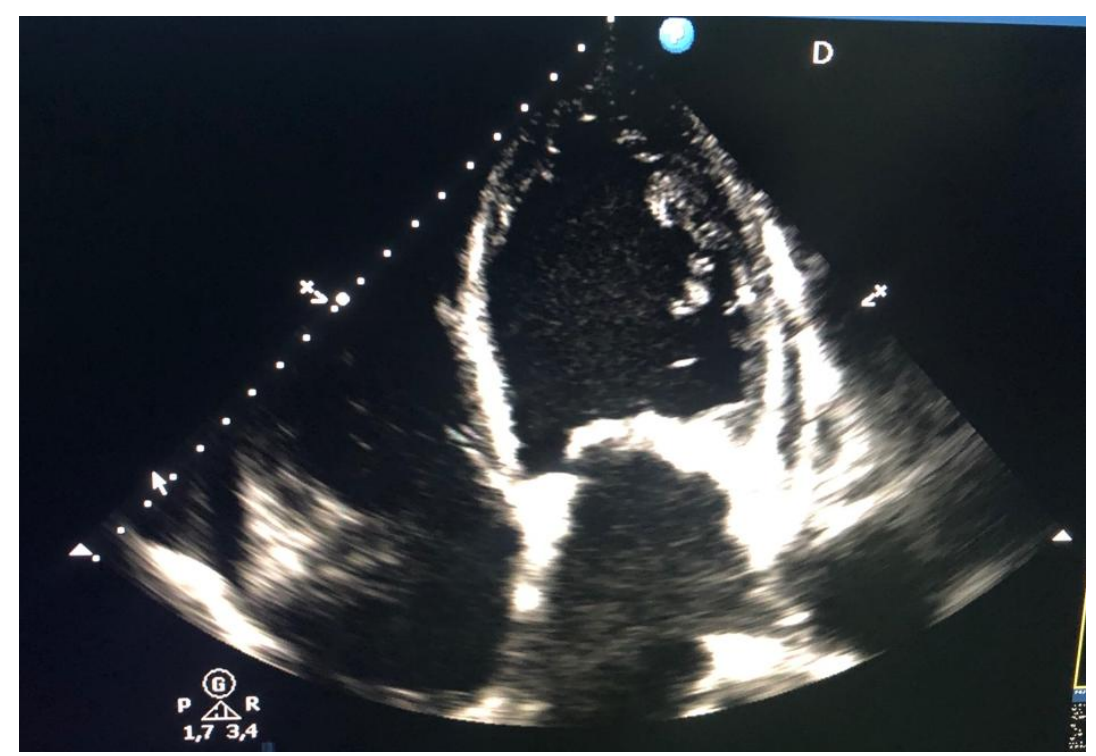

Fig-1: Mitral vegetetaion with mitral stenosis

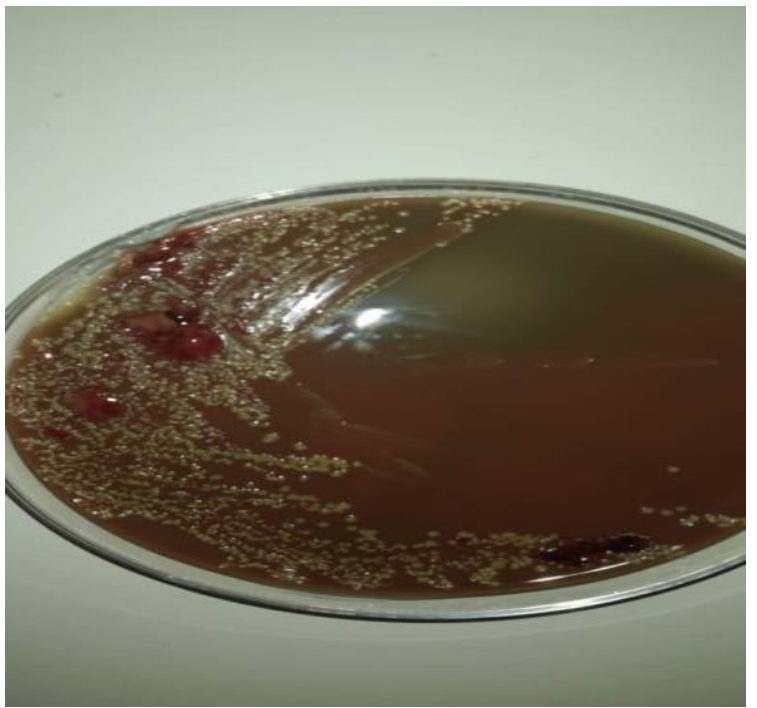

Fig-2: Positive blood culture to staphylococcus aureus

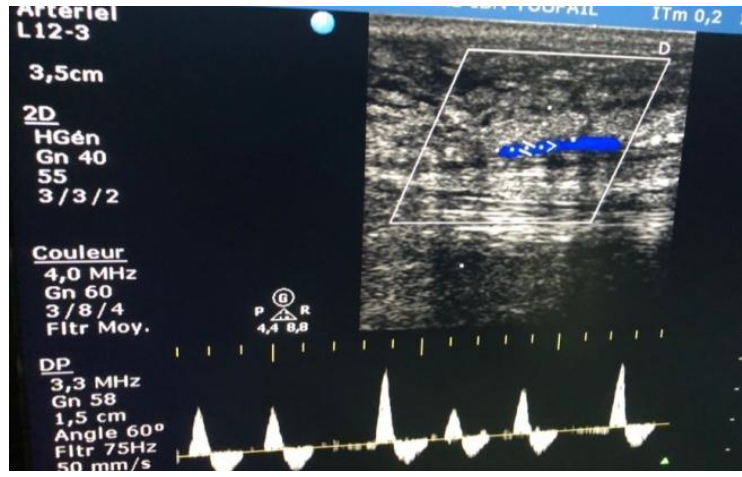

Fig-3: Iliofemoral occlusion with throbosis and demodulated flow

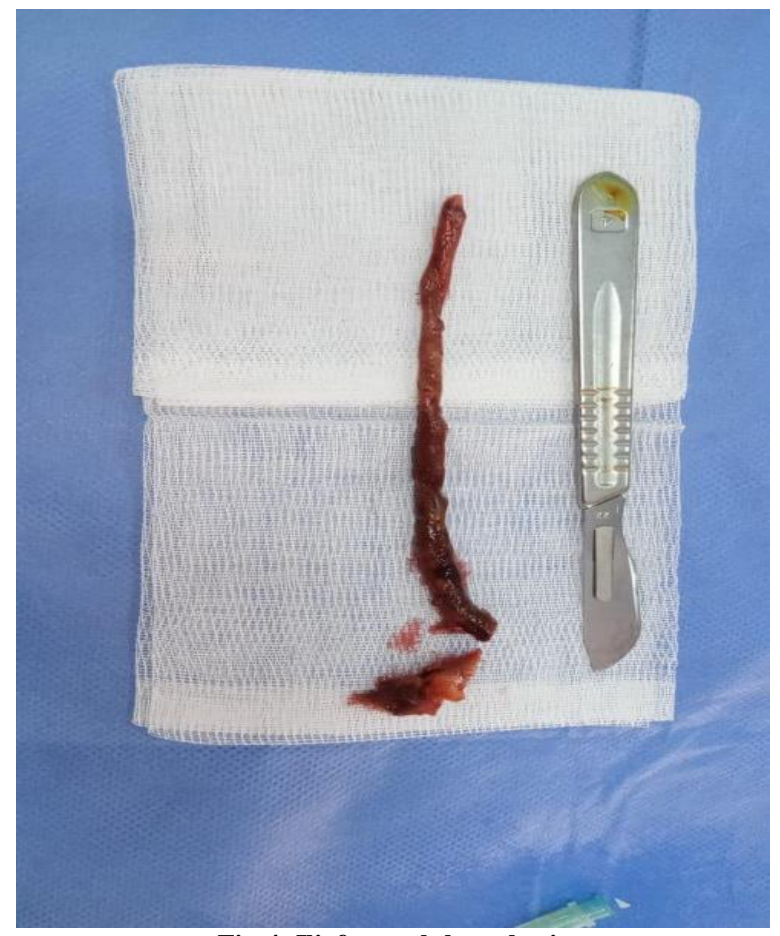

Fig-4: Iliofemoral thrombosis 


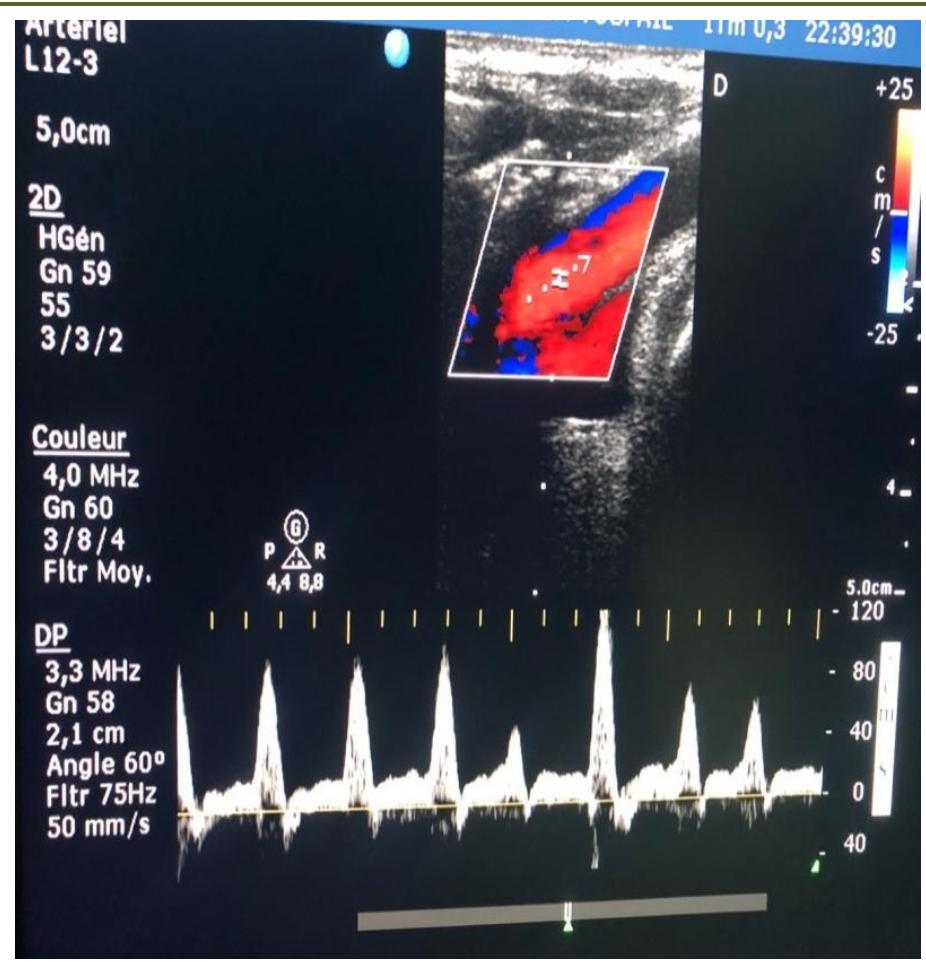

Fig-5: Flow restoration after Fogarty embolectomy

\section{DISCUSSION}

Acute Limb ischemia is a rare complication of infectious endocarditis [1]. This case report presents an infectious endocarditis caused by Staphylococcus aureus complicated with acute right lower limb ischemia.

Afterthe management of acute lower limb ischemia with revascularization with fogarty catheter, we opted for surgical treatment by performing a mitral valve replacement and tricuspid valve plasty.

Vascular complications of infectious endocarditis are frequent [2, 3]. Peripheric emboly, including cerebral strokes $[4,5]$, myocardial infarction [6] and pulmonary embolism [7] have been reported in case of infectious endocarditis. However, lower limbs thromboemlism are rare with incidence of $4 \%-5 \%$ in patients with native valve endocarditis $[8,9]$.

The general approach for an effective management of IE is initial clinical stabilization, early acquisition of blood cultures, an aggressive medical and/or surgical treatment [10]. Antibiotic treatment depends on whether the valve is native or prosthetic, as well as on the identified microorganism and its antibiotic sensitivity. After diagnosing endocarditis according to modified Duke criteria, an empirical antibiotic treatment was started (Ceftriaxon $2 \mathrm{~g}$ and gentamycin $160 \mathrm{mg}$ ).

Valve replacement is suggested in patients with multiple or recurrent embolic events [11]. Early surgery may be recommended for patients with vegetations $>15 \mathrm{~mm}$ with high mobility, important valve destruction, heart failure and non-response to antibiotic therapy [12].

\section{CONCLUSION}

Our case report shows an uncommun case of infectious endocarditis complicated with peripheral embolism of the common femoral artery and acute lower limb ischemia. Aggressive antibiotic therapy associated to Fogarty embolectomy and a delayed surgery for mitral valve replacement with tricuspid plasty have led to good clinical and biological outcomes.

\section{REFERENCES}

1. Galyfos G, Giannakakis S, Kerasidis S, Geropapas G, Kastrisios G, Papacharalampous G, Maltezos C. Infective endocarditis as a rare cause for acute limb ischemia. World journal of emergency medicine. 2016;7(3):231.

2. Gould, F. K., Denning, D. W., Elliott, T. S., Foweraker, J., Perry, J. D., Prendergast, B. D., ... \& Watkin, R. W. (2012). Guidelines for the diagnosis and antibiotic treatment of endocarditis in adults: a report of the Working Party of the British Society for Antimicrobial Chemotherapy. Journal of antimicrobial chemotherapy, 67(2), 269-289.

3. Pessinaba S, Kane A, Ndiaye MB, Mbaye A, Bodian M, Dia MM, Sarr SA, Diao M, Sarr M, Kane A, Ba SA. Vascular complications of infective endocarditis. Médecine et maladies infectieuses. 2012 May 1;42(5):213-7.

4. Fukuda W, Daitoku K, Minakawa M, Fukui K, Suzuki Y, Fukuda I. Management of infective 
endocarditis with cerebral complications. Ann Thorac Cardiovasc Surg. 2014;20:229-236.

5. Tisdell J, Smith TW, Muehlschlegel S. Multiple septic brain emboli in infectious endocarditis. Arch Neurol. 2012;69:1206-1207.

6. Yeoh J, Sun T, Hobbs M, Looi JL, Wong S. An uncommon complication of infective bacterial endocarditis. Heart Lung Circ. 2012;21:811-814.

7. Reinders S, Bogaard K, Reichert CL, Knol RJ. A tortuous road for septic pulmonary emboli in leftsided endocarditis. Can Journal Cardiol. 2014;30:1462.

8. Uglov AI, Diuzhikov AA. Surgery of arterial embolism in patients with infective endocarditis. Angiologiia i sosudistaia khirurgiia $=$ Angiology and vascular surgery. 2004;10(3):97-103.
9. Souilhem J, Chapelon C, Raguin G, Wechsler B, Blétry O, Godeau P. Arterial embolism of the limbs in infectious endocarditis of the heart valves. Presse medicale (Paris, France: 1983). 1990 Jun;19(25):1177-81.

10. Sett SS, Hudon MP, Jamieson WR, Chow AW. Prosthetic valve endocarditis. Experience with porcine bioprostheses. Journal Thorac Cardiovasc Surg. 1993;105:428-434

11. Souilhem J, Chapelon C, Raguin G, Wechsler B, Blétry O, Godeau P. Arterial embolism of the limbs in infectious endocarditis of the heart valves. Presse medicale (Paris, France: 1983). 1990 Jun;19(25):1177-81.

12. Sabe MA, Shrestha NK, Menon V. Contemporary drug treatment of infective endocarditis. Am Journal Cardiovasc Drugs. 2013;13:251-258. 